\title{
Correspondence
}

\section{The dying don't need analytic psychotherapy}

\section{SIR}

Dr Lawrence Goldie, foumal of medical ethics, September 1982: 128-133, made some telling comments concerning the apparent inability of many doctors and nurses to take the necessary time and trouble to tell patients the truth and help them cope with it. He did not, however, concern himself too much with why it is that after so many similar exhortations from himself and others concerning the need for time, trouble, talk and tolerance, the situation seems to remain unchanged. One possible answer I would suggest lies within his own article. For, having persuasively argued the need for a doctor to communicate properly, to listen carefully, to question intelligently and to counsel sympathetically, Dr Goldie then transmogrifies such a doctor into a 'psychotherapist' and advances the non sequitur that the appropriate interviewing method is derived from 'psychoanalysis and psychotherapy'.

Yet every example of poor communication advanced by him in his article points to the need for much more valid and justified psychological skills than those derived from psychodynamic psychotherapy. The patient whose GP never warned him of the possibility that his blood tests might reveal a serious disease did not need a therapist steeped in oedipal theory and ego psychology; he needed a doctor able to communicate simply, straightforwardly and sympathetically. 'Mrs S' benefited from being given the opportunity by $\mathrm{Dr}$ Goldie to review her past life, muse on her fortunes as well as her misfortunes and prepare herself for her death. There is no evidence, in his text at any rate, that what he did for her required any elaborate or technical psychotherapeutic skill. 'Psychotherapy' declares Dr Goldie, 'uses the psychoanalytic technique in searching for the truths which will help people to reduce unnecessary suffering and survive it when it is inevitable'. Quite what these techniques are is not at all clear from his article. But the techniques which are commonly referred to as psychoanalytic involve the measured interpretation of unconscious conflicts and mechanisms of defence leading eventually to the establishment of a transference neurosis through which the genesis of infantile conflicts and their intrusion into the present life of the patient may be resolved. Whatever one might say about the merits of this approach elsewhere it does not seem to have any obvious justification in the circumstances described by Dr Goldie.

This is not an academic issue. Many GPs, hospital doctors and nurses appear to share Dr Goldie's confusion and assume that any form of psychological intervention, if it is to be any good, must be infused with psychoanalytic values and techniques. Many of them, lacking Dr Goldie's familiarity with such matters, understandably shy away from talking to their patients, fearing that their untutored efforts will cause damage and that 'appropriate' psychotherapy requires a time-consuming training and a familiarity with a complicated metapsychology. Dr Goldie only reinforces such misconceptions in my view.

In fact, there is a growing body of evidence (I) which suggests that by using much more basic psychological skills doctors can bring about improvements in the doctor-patient consultation and even in patient outcome which compare quite favourably with those achieved by more timeconsuming methods or more highlytrained therapists. The most urgent priority at the present time would appear to be improving the basic interviewing skills of doctors and others engaged in the clinical management of patients. The skills concerned include the provision and probing of verbal an non-verbal cues, the use of open-endeof questions, the maintenance of good eye-to-eye contact, the ability to listein without being overwhelmed by the gareo rulous and the nervous, and the judicis ous use of time.

It is these and allied skills, whicb have little to do with psychoanalysis oo indeed with psychoanalytically-derive psychotherapy, which we should be developing and fostering in doctors and nurses. It is interesting to note that had. those who were responsible for the gares of the patients in the various example $\$$ provided by Dr Goldie possessed sucto skills to a reasonably developed de then the complications which repero tedly ensued would almost certainl have been avoided.

\section{References}

(I) Goldberg D, Steele J J, Johnson A Smith C. Ability of primary care physicians to make accurate ratings of psychiatric symptoms. Archives of general psychiatry 1982; $3 \%$ 829-833; Hogan D. B. The regula tion of psychotherapists. Cambridge Mass, USA: Ballinger Publishing Company, 1979; Marks J NG Goldberg D P, Hillier V F. Detek minants of the ability of generab practitioners to detect psychiatrie illness. Psychological medicine; 197 9: 337-353.

ANTHONY W CLARO

Deputy Director

General Practice Research Un

Institute of Psychiatry, Londow

Confidentiality and occupational health physicians

\section{SIR}

While clearing out an old filing cabinet $\Phi$ came across the enclosed letter. It seem 